\title{
ARTIGO
}

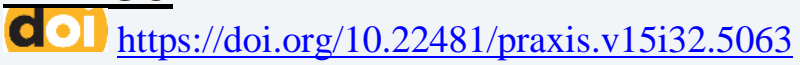

\section{TRABALHO DOCENTE NA LICENCIATURA EM CIÊNCIAS BIOLÓGICAS: UMA ANÁLISE A PARTIR DO ESTADO DA QUESTÃo}

\author{
THE ROLE OF TEACHERS IN THE TEACHING DEGREE IN BIOLOGICAL SCIENCES: \\ AN ANALYSIS BASED ON THE STATE OF THE QUESTION
}

\author{
TRABAJO DOCENTE EN LA LICENCIATURA EN CIENCIAS BIOLÓGICAS: \\ UN ANÁLISIS A PARTIR DEL ESTADO DE LA CUESTIÓN
}

\begin{abstract}
Maria Márcia Melo de Castro Martins Universidade Estadual do Ceará - Brasil
\end{abstract}

Maria Marina Dias Cavalcante Universidade Estadual do Ceará - Brasil

Elisangela André da Silva Costa Universidade da Integração Internacional da Lusofonia Afro-Brasileira - Brasil

\begin{abstract}
Resumo: O estudo, do tipo Estado da Questão (EQ), objetivou identificar pesquisas que discutam o trabalho docente na Licenciatura em Ciências Biológicas, na perspectiva da Ontologia do Ser Social, ou ontologia marxiano-lukacsiana. Compõe um momento investigativo da pesquisa de doutoramento em desenvolvimento no âmbito do Programa de Pós-graduação em Educação da Universidade Estadual do Ceará (PPGE - UECE), intitulada "Trabalho Docente na Licenciatura em Ciências Biológicas: uma análise na perspectiva da ontologia marxiano-lukacsiana". Foram analisadas produções localizadas na Biblioteca Digital de Teses e Dissertações (BDTD), no Portal.Periódicos.CAPES (Base Scielo), nos Anais da Associação Nacional de Pós-graduação e Pesquisa em Educação (ANPED) e no Banco de Teses e Dissertações do PPGE - UECE. O EQ revelou que o trabalho docente tem se constituído como objeto de investigação sob diversos enfoques e compreendido a partir de variados percursos metodológicos. Contudo, não foram encontradas investigações que o abordassem como um complexo que tem sua gênese no trabalho (transformação da natureza pelo homem), ato fundante do ser social, mediação entre o indivíduo e o gênero humano, nem, ainda, investigado a partir do Materialismo Histórico Dialético. Tal achado sinaliza uma lacuna no campo das investigações sobre o trabalho docente na licenciatura em questão e a possibilidade de nossa pesquisa contribuir para ampliar o debate no campo acadêmico-científico no tocante ao trabalho dos professores formadores nas licenciaturas e, no caso específico da tese em andamento, da formação de professores de Ciências e Biologia para a Educação Básica.
\end{abstract}

Palavras -chave: Licenciatura em ciências biológicas; Ontologia do ser social; Trabalho docente. 
Abstract: This study, based on the State of the Question, aimed to identify researches which discuss the role of teachers in the Teaching Degree in Biological Sciences from the perspective of the Ontology of the Social Being, or the Marx-Lukacs ontology. This investigation is part of the doctoral research on development in the Graduate Program in Education at the State University of Ceará (PPGE - UECE), entitled "The Role of Teachers in the Teaching Degree in Biological Sciences: an analysis made from the perspective of the Marx-Lukacs ontology". We have analyzed publications found at the Thesis and Dissertation Digital Library (BDTD), on the CAPES/Coordination for the Improvement of Higher Education Personnel Journal Portal (SciELO/Scientific Electronic Library Online Database), in the Publications of the National Association for Graduation and Research on Education (ANPED), and in the PPGE-UECE Thesis and Dissertation Database. The State of the Question study showed that the role of teachers has become the focus of investigation from different perspectives and has been understood based on various methodologies. However, there was no evidence of investigation regarding it as a complex originated from work (man-made changes to the natural world), an act that formed the social being, mediation between man and the human kind, nor that it has been investigated based on the Dialectical and Historical Materialism. Such finding shows a gap in the investigations on the role of teachers in the teaching degree discussed here, and our research as a contribution to broaden the debate in the academic-scientific field regarding the role of teacher trainers in teaching degree programs and, in the specific case of the thesis in progress, the training of Basic Education teachers of Sciences and Biology.

Keywords: Teaching Degree in Biological Sciences. Ontology of the social being. The role of teachers.

Resumen: El estudio, del tipo Estado de la Cuestión (EQ), tiene como objetivo identificar investigaciones que discutan el trabajo docente en la Licenciatura en Ciencias Biologicas, dentro de la perspectiva de la Ontología del Ser Social, o Ontología marxista-lukacsiana. En el marco del Programa de Pos-graduação da Universidade Estadual do Ceará (PPGE - UECE), titulado: Trabajo Docente en la Licenciatura en Ciencias Biológicas: Un análisis desde la perspectiva de la ontología marxistalukacsiana. Se analizaron las producciones encontradas en la Biblioteca Digital de Tesis y Disertações - BDTD, en el Portal Periódicos. CAPES (Base Scielo), en los Anales de la Associação Nacional de Pós-graduação e Pesquisa em Educação - ANPED, y em el Banco de Tesis y Disertaciones del PPGE UECE. El EQ reveló que el trabajo docente se há constituido como objeto de investigación bajo diversos enfoques y comprendido a partir de variados itinerarios metodológicos. Sin embargo, no se encontraron investigaciones que lo abordaran como un complejo que tiene su génesis em el trabajo (transformación de la naturaleza por el hombre, acto fundante del ser social, mediación entre el individuo y el género humano), ni aún siendo investigado en base a los postulados del Materialismo Histórico Dialéctico. Tal descobrimiento señala una importante laguna o vacío en el campo de las investigaciones sobre el trabajo docente en la licenciatura en cuestión, y la posibilidad cierta de que nuestra investigación contribuya a ampliar el debate en el campo académico-científico, en lo referente al trabajo de los profesores a cargo de la formación de futuros licenciados y, en el caso específico de la tesis en marcha, de la formación de profesores de Ciencias y Biología para la Educación Básica.

Palabras clave: Licenciatura en ciencias biologicas; Ontologia del ser social; Trabajo docente.

\section{Introdução}

Este artigo expressa o movimento que realizamos no intuito de conhecermos as produções acadêmico-científicas relacionadas ao trabalho docente na Licenciatura em Ciências Biológicas, objeto de estudo da tese em desenvolvimento no âmbito do Programa de Pós-graduação em Educação da Universidade Estadual do Ceará, provisoriamente, 
intitulada"Trabalho docente na Licenciatura em Ciências Biológicas: uma análise a partir da perspectiva marxiano-lukacsiana", resultando na elaboração do Estado da Questão (EQ). Isso porque "o processo de pesquisa exige conhecer o que já existe produzido sobre determinado tema que se quer estudar [...] (NUNES, 2010, p.25).

Segundo Therrien e Nóbrega-Therrien (2004, p. 7): “A finalidade do 'Estado da Questão' é de levar o pesquisador a registrar, a partir de um rigoroso levantamento bibliográfico, como se encontra o tema ou o objeto de sua investigação no estado atual da ciência ao seu alcance". Assim, como etapa inicial da investigação, a realização desse procedimento nos revelou escassez de pesquisas sobre o trabalho docente desenvolvido na licenciatura, e particularmente na Licenciatura em Ciências Biológicas, a partir do referencial teórico-metodológico que está embasando a investigação em questão: a Ontologia do Ser social e o Materialismo Histórico Dialético1. Em nossa investigação estamos assumindo a emancipação humana como o horizonte da formação e do trabalho docente (TONET, 2014).

Localizamos, num universo de dez mil duzentas e três (10.203) produções, distribuídas em quatro fontes de busca, novecentas e noventa e uma (991) relacionadas ao tema da tese, das quais selecionamos cento e trinta e duas (132). Destas, analisamos trinta e três (33), das quais dezesseis $(16)^{2}$ tratam de pesquisas realizadas no âmbito da Licenciatura em Ciências Biológicas e que para efeito deste estudo serão tomadas como objetos de análise.

A partir do exposto, este estudo tem por objetivo explicitar, a partir da realização do Estado da Questão, os enfoques e percursos metodológicos das investigações realizadas no âmbito da referida Licenciatura, envolvendo o trabalho do professor formador.

\section{Metodologia}

As buscas em torno do objeto de investigação- o trabalho docente na licenciatura em Ciências Biológicas - foram realizadas, num primeiro momento (setembro e outubro de 2016), na Biblioteca Digital de Teses e Dissertações (BDTD) e no Portal Periódicos CAPES (Base Scielo) e, num segundo momento (março e abril de 2017), nos anais das Reuniões Anuais da Associação Nacional de Pós-graduação e Pesquisa em Educação - ANPED e no

\footnotetext{
${ }^{1}$ Método que assumimos no decorrer da investigação, na medida em que fomos adentrando aos estudos da Ontologia do Ser Social. Assim, o Materialismo Histórico Dialético não constou em nossas buscas, inicialmente, mas foi considerado na análise das produções que selecionamos para a elaboração do EQ. Na busca que realizamos, os estudos relacionados à Licenciatura, e particularmente à Licenciatura em Ciências Biológicas, não explicitam ancoragem no referido método.

${ }^{2}$ Ferreira (2010); Brito (2006, 2011); Madeira (2014); Furlani (1994); Martelli (2004); Bizarro (2005); Gatti (2010); Freitas Et Al (2012); Massabini (2011); Pereira (2000); Silva; Schnetzler (2004); Teixeira (2012); Cardoso (2011); Medeiros (2017) e Lotffi (2014).
} 
site do Programa de Pós-graduação em Educação da Universidade Estadual do Ceará (PPGEUECE).

Intencionávamos, ainda, sondar o Banco de Teses e Dissertações da CAPES, mas, no período informado, o mesmo passava por atualização, daí nossa opção, naquele momento, apenas pela BDTD. A escolha por essas bases se deu em decorrência de se constituírem fontes reconhecidamente relevantes no meio científico-acadêmico, tanto em âmbito nacional (BDTD, Portal. Periódicos.CAPES/ Base Scielo e ANPED) quanto local (PPGE/UECE). A seguir, justificamos, mais explicitamente, a escolha das fontes que utilizamos para a composição do Estado da Questão.

No Portal.Periódicos.CAPES, uma das principais iniciativas brasileiras para acesso à informação por parte da comunidade acadêmica, podemos acessar bases de dados de resumos, relatórios, etc. $\mathrm{O}$ mesmo disponibiliza uma expressiva quantidade de títulos de periódicos científicos nacionais e internacionais, teses e dissertações, assim como bases de dados referenciais, com resumos de documentos em todas as áreas do conhecimento. Dentre as Bases de dados que o Portal comporta, está a Scielo - Scientific Eletronic Library Online (Biblioteca Científica Eletrônica em Linha), esta de interesse especial para a Educação, pois compreende periódicos do Brasil, de outros países da América Latina e África, Espanha e Portugal. Nesse banco podem ser consultados artigos e periódicos empregando-se diversos filtros (NUNES, 2010).

A BDTD, mantida pelo Instituto Brasileiro de Informação em Ciência (IBICIT), é outra iniciativa brasileira que congrega uma expressiva quantidade de teses e dissertações defendidas em instituições brasileiras. Além do Portal.Periódicos.CAPES (Base Scielo) e da BDTD, os eventos e associações profissionais, a exemplo da ANPED, também constituem importantes fontes de consulta sobre publicações acadêmico-científicas (NUNES, 2010).

O banco de teses e dissertações do PPGE/UECE também compôs nossa escolha por se tratar de um Programa com concentração em formação de professores, com linhas e núcleos de pesquisa nos âmbitos do Trabalho docente (Formação, Didática e Trabalho Docente) e do Marxismo (Marxismo e Formação do Educador; Marxismo e Ontologia do Ser Social).

A busca das produções na BDTD considerou os descritores: Docência Universitária, Trabalho Docente e Formação de Professores combinados a outros: Licenciatura em Ciências Biológicas; Ontologia Lukacsiana; Lukács; Professor universitário; Ensino Superior; Formação de Professores de Biologia e Biologia. Ressaltamos que não realizamos recorte temporal para essas bases, contudo lançamos mão da opção busca avançada, por meio da utilização da combinação dos referidos descritores. 
A segunda base de dados consultada foi a do Portal.Periódicos.CAPES. Nesta, buscamos pelos mesmos descritores informados à BDTD, utilizamos também alguns filtros na seleção dos trabalhos:

a) revisados por pares;

b) depositados na ScieloBrazil;

c) em Língua Portuguesa.

Lançamos mão da combinação de descritores, utilizando booleanos (AND). Assim como nas buscas à BDTD, não delimitamos recorte temporal, e também não indicamos intenção de Qualis para os trabalhos, no intuito de realizarmos uma busca ampliada, haja vista que no levantamento realizado na BDTD não localizamos pesquisas que discutissem o trabalho docente na perspectiva do nosso referencial teórico-metodológico.

A busca nas reuniões anuais da Anped foi realizada em material disponível online, nos Grupos de Trabalho (GT): 04 - Didática; 08 - Formação de Professores; GT 09 - Trabalho e Educação, compreendendo o período de 2000 a $2015^{3}$. Optamos por consultar os trabalhos da modalidade Comunicações Orais pela maior extensão do conteúdo, se comparados aos Pôsteres.

No site da Anped não é possível utilizar descritores ou filtros para a localização de produções nos GT. Nesse caso, procedemos à leitura dos títulos e dos resumos nos três Grupos de Trabalho mencionados. Em algumas reuniões não estão disponibilizados os resumos, o que nos conduziu à leitura da introdução dos textos. A busca considerou os estudos relacionados aos descritores: Trabalho docente; Trabalho docente no Ensino Superior; Trabalho docente na Licenciatura; Trabalho docente na Licenciatura em Ciências Biológicas/ Docência Universitária e termos associados a trabalho docente.

Por fim, a busca no Banco de Dados do PPPGE/UECE se deu considerando o período de 2006 (ano em que foram defendidas as dissertações da primeira turma do PPGE/UECE, à época, Curso de Mestrado Acadêmico da UECE - CMAE/UECE) a 2017 (ano em que realizamos a consulta).

\section{0 que dizem as produções acadêmico-científicas}

Como informamos na introdução deste artigo, localizamos, a partir das buscas nas quatro fontes, um universo de dez mil duzentas e três (10.203) produções, novecentas e noventa e uma (991) relacionadas ao tema da tese, das quais selecionamos cento e trinta e

\footnotetext{
${ }^{3}$ Não estão disponibilizados, online, os trabalhos das reuniões da ANPED anteriores ao ano 2000.
} 
duas (132). Destas, analisamos trinta e três (33), das quais dezesseis (16) tratam de pesquisas realizadas no âmbito da Licenciatura em Ciências Biológicas, conforme apresentamos no quadro 1:

Quadro 1 - Síntese quantitativa das produções localizadas na BDTD, Portal.Periódicos.CAPES, Anped, PPGE/UECE

\begin{tabular}{|l|l|l|l|c|c|}
\hline Fontes & $\begin{array}{l}\text { Total de } \\
\text { registros }\end{array}$ & $\begin{array}{l}\text { Trabalhos } \\
\text { relacionados } \\
\text { ao tema }\end{array}$ & $\begin{array}{l}\text { Trabalhos } \\
\text { selecionados }\end{array}$ & $\begin{array}{l}\text { Trabalhos } \\
\text { analisados }\end{array}$ & $\begin{array}{l}\text { Trabalhos analisados } \\
\text { no âmbito da } \\
\text { Licenciatura em } \\
\text { Ciências Biológicas }\end{array}$ \\
\hline BDTD & 4.133 & 474 & 28 & 07 & 07 \\
\hline $\begin{array}{l}\text { PORTAL. } \\
\text { PERIÓDCOS. } \\
\text { CAPES }\end{array}$ & 4.634 & 429 & 22 & 09 & 04 \\
\hline ANPED & 754 & 64 & 61 & 12 & 02 \\
\hline PPGE/UECE & 182 & 24 & 21 & 05 & 03 \\
\hline Total & 10.203 & 991 & 132 & 33 & 16 \\
\hline
\end{tabular}

Fonte: elaboração das autoras

As investigações realizadas no âmbito da Licenciatura em Ciências Biológicas foram explicitadas no quadro 2 :

Quadro 2 - Distribuição dos enfoques das pesquisas sobre trabalho docente na Licenciatura em Ciências Biológicas, a partir das fontes consultadas (BDTD; Portal.Periódicos.CAPES; ANPED; PPGE/UECE).

\begin{tabular}{|c|c|c|c|}
\hline Assunto/autor/ano & $\begin{array}{l}\text { Método/ } \\
\text { Procedimentos } \\
\text { explicitados }\end{array}$ & Formas de busca & Fonte \\
\hline $\begin{array}{lcr}\text { Prática } & \text { docente do } \\
\text { professor } & \text { formador } \\
\text { (FERREIRA, 2010) }\end{array}$ & $\begin{array}{l}\text { Estudo } \\
\text { Caso/Entrevista } \\
\text { semiestruturada }\end{array}$ & $\begin{array}{l}\text { Combinação dos } \\
\text { descritores: } \\
\text { Docência Universitária/ } \\
\text { Formação } \\
\text { professores }\end{array}$ & \multirow[t]{5}{*}{ BDTD } \\
\hline $\begin{array}{lr}\text { Ciclo de vida profissional } \\
\text { dos } & \text { professores } \\
\text { formadores } & \text { (BRITO, } \\
2011 \text { ) } & \end{array}$ & $\begin{array}{l}\text { História Oral } \\
\text { Temática/Entrevista } \\
\text { temática }\end{array}$ & \multirow{4}{*}{$\begin{array}{l}\text { Combinação dos } \\
\text { descritores: } \\
\text { Formação de } \\
\text { professores/Professor } \\
\text { universitário }\end{array}$} & \\
\hline $\begin{array}{l}\text { Representações dos } \\
\text { professores formadores } \\
\text { sobre a docência e suas } \\
\text { relações com a prática } \\
(\text { BRITO, 2006) }\end{array}$ & $\begin{array}{l}\text { Representações } \\
\text { sociais/Questionário e } \\
\text { entrevista }\end{array}$ & & \\
\hline $\begin{array}{l}\text { Trabalho dos professores } \\
\text { de disciplinas específicas } \\
\text { na formação dos } \\
\text { licenciandos } \\
\text { (MADEIRA, 2014) }\end{array}$ & $\begin{array}{l}\text { Etnopesquisa crítica e } \\
\text { aplicada/narrativas } \\
\text { docentes }\end{array}$ & & \\
\hline $\begin{array}{lll}\text { Relação } & \text { trabalho } & \text { do } \\
\text { professor formador } & \mathrm{e}\end{array}$ & $\begin{array}{ll}\text { Teoria Crítica } & \text { da } \\
\text { Educação, a partir } & \text { de }\end{array}$ & & \\
\hline
\end{tabular}




\begin{tabular}{|c|c|c|c|}
\hline $\begin{array}{lr}\text { formação } & \text { dos } \\
\text { licenciandos } & \text { (FURLANI, } \\
\text { 1994) } & \end{array}$ & $\begin{array}{l}\text { Habermas/ } \\
\text { Questionário }\end{array}$ & & \\
\hline $\begin{array}{l}\text { Significado da Didática } \\
\text { na prática pedagógica do } \\
\text { professor de Licenciatura } \\
\text { (BIZARRO, 2005) }\end{array}$ & $\begin{array}{l}\text { Pesquisa } \\
\text { qualitativa/Entrevista e } \\
\text { observação em sala de } \\
\text { aula }\end{array}$ & \multirow{2}{*}{$\begin{array}{ll}\text { Combinação } & \text { dos } \\
\text { descritores: } & \\
\text { Formação } & \text { de } \\
\text { professores/Ensino } & \\
\text { Superior } & \end{array}$} & \\
\hline $\begin{array}{l}\text { Referenciais teóricos para } \\
\text { formação dos } \\
\text { licenciandos e o trabalho } \\
\text { do docente formador } \\
\text { (MARTELLI, 2004) }\end{array}$ & $\begin{array}{l}\text { Pesquisa qualitativa/ } \\
\text { Questionário aberto }\end{array}$ & & \\
\hline $\begin{array}{l}\text { Formação de professores } \\
\text { no Brasil, com foco nas } \\
\text { licenciaturas em } \\
\text { Pedagogia, Matemática, } \\
\text { Língua Portuguesa e } \\
\text { Ciências Biológicas } \\
\text { (GATTI, 2010) }\end{array}$ & Pesquisa documental & \multirow[t]{4}{*}{$\begin{array}{l}\text { Descritor: } \\
\text { Formação } \\
\text { professores }\end{array}$} & \multirow[t]{4}{*}{$\begin{array}{l}\text { Portal Periódicos } \\
\text { CAPES/ Base } \\
\text { ScieloBrazil }\end{array}$} \\
\hline $\begin{array}{l}\text { Formação de professores } \\
\text { das licenciaturas de } \\
\text { Física, Biologia e } \\
\text { Matemática (FREITAS et } \\
\text { al, 2012) }\end{array}$ & $\begin{array}{l}\text { Pesquisa colaborativa } \\
\text { do tipo interventiva }\end{array}$ & & \\
\hline $\begin{array}{l}\text { Conflitos vivenciados por } \\
\text { licenciandos em Ciências } \\
\text { Biológicas durante o } \\
\text { Estágio Supervisionado e } \\
\text { a relação com o trabalho } \\
\text { do professor formador } \\
\text { (MASSABINI, 2011) }\end{array}$ & $\begin{array}{l}\text { Pesquisa } \\
\text { Empírica com cinco } \\
\text { licenciandos/ } \\
\text { Questionário } \\
\text { (situações hipotéticas) }\end{array}$ & & \\
\hline $\begin{array}{lr}\text { Situação de } & \text { menor } \\
\text { acadêmico } & \text { das } \\
\text { licenciaturas } & \text { nas } \\
\text { universidades rasileiras } \\
\text { (PEREIRA, 2000) }\end{array}$ & \begin{tabular}{lr} 
Investigação & \multicolumn{2}{r}{ sócio- } \\
históricarealizada no \\
curso de licenciatura \\
em & Ciências \\
Biológicas rr da \\
Universidade Federal \\
de minas Gerais - \\
UFMG / Estudo de \\
Caso
\end{tabular} & & \\
\hline $\begin{array}{l}\text { Mediação do trabalho do } \\
\text { professor formador na } \\
\text { constituição de futuros } \\
\text { docentes e elaboração do } \\
\text { conhecimento científico } \\
\text { (SILVA; SCHNETZLER, } \\
\text { 2004) }\end{array}$ & $\begin{array}{l}\text { Perspectiva histórico- } \\
\text { cultural/ Observação } \\
\text { de aula }\end{array}$ & \multirow[t]{2}{*}{$\begin{array}{l}\text { Sem descritores/ } \\
\text { Busca nos } \\
\text { título dos } \text { trabalhos/ } \\
\text { resumos/ } \\
\text { Introdução }\end{array}$} & \multirow[t]{2}{*}{ ANPED } \\
\hline $\begin{array}{l}\text { Mediação didática no } \\
\text { contexto da universidade } \\
\text { (TEIXEIRA, 2012) }\end{array}$ & $\begin{array}{ll}\text { Representações } & \\
\text { Sociais; } & \\
\text { Pesquisa quanti- } \\
\text { qualitativa/ } \\
\text { Questionário; } \\
\text { Entrevista. } \\
\end{array}$ & & \\
\hline
\end{tabular}




\begin{tabular}{|c|c|c|c|}
\hline $\begin{array}{l}\text { Prática } \\
\text { universitária do professor } \\
\text { de Ciências Biológicas } \\
\text { (licenciatura) } \\
\text { Universidade Estadual do } \\
\text { Ceará, integrando ensino } \\
\text { e pesquisa (CARDOSO, } \\
2011 \text { ) }\end{array}$ & $\begin{array}{l}\text { Etnometodologia/ } \\
\text { análise documental, } \\
\text { observação } \\
\text { entrevista. }\end{array}$ & $\begin{array}{l}\text { Sem descritores/ } \\
\text { Busca no banco de teses } \\
\text { e dissertações /por título } \\
\text { dos trabalhos/ resumos/ } \\
\text { Introdução. }\end{array}$ & $\begin{array}{l}\text { PPGE/ } \\
\text { UECE }\end{array}$ \\
\hline $\begin{array}{l}\text { A práxis pedagógica do } \\
\text { docente de Ciências } \\
\text { Biológicas (licenciatura) } \\
\text { da Universidade Estadual } \\
\text { ao Ceará e contribuições } \\
\text { da Didática para o } \\
\text { exercício da docência } \\
\text { (LOTFFI, 2014) }\end{array}$ & $\begin{array}{l}\text { Estudo de caso; } \\
\text { Entrevista } \\
\text { semiestruturada; } \\
\text { Análise de conteúdo }\end{array}$ & & \\
\hline $\begin{array}{l}\text { Significados produzidos } \\
\text { pelo currículo de } \\
\text { licenciatura e sua relação } \\
\text { com a identidade docente } \\
\text { dos professores Curso de } \\
\text { Ciências Biológicas/ } \\
\text { CCS/UECE } \\
\text { (MEDEIROS, 2017) }\end{array}$ & $\begin{array}{l}\text { Estudo de caso/ análise } \\
\text { documental; } \\
\text { Entrevista; } \\
\text { Roda de conversa }\end{array}$ & & \\
\hline
\end{tabular}

Fonte: elaboração das autoras

3.1 O que dizem as produções da Biblioteca Digital de Teses e Dissertações - BDTD?

Conforme o quadro 1, foram sete (07) as investigações localizadas na BDTD: cinco (05) dissertações (BIZARRO, 2005; BRITO, 2006; FERREIRA, 2010; FURLANI, 1994; MARTELLI, 2004) e duas (02) teses (BRITO, 2011; MADEIRA, 2014).

Ferreira (2010) buscou compreender como alguns formadores da licenciatura em Ciências Biológicas da Universidade Federal de Goiás concebem suas práticas e quais as vivências formativas proporcionam aos futuros egressos do referido curso. Constatou que a maioria dos formadores não articula os conhecimentos teóricos aos práticos para uma atuação crítica, consciente e comprometida com a profissionalização e com as mudanças que esta provoca na realidade social da qual fazem parte. Seu trabalho aponta necessidade de haver uma política de formação de professores que valorize a docência como uma atividade profissional no âmbito da universidade.

A investigação contribui para a consolidação do entendimento de que há limitações ao desenvolvimento do trabalho docente na licenciatura na perspectiva da emancipação humana, haja vista as fragilidades que marcam seu processo formativo e os desafios que se apresentam no campo da formação de professores. Essa é uma determinação importante do trabalho do 
professor, uma vez que o domínio dos conteúdos específicos a serem ensinados constitui uma das exigências para o desenvolvimento de uma atividade educativa de caráter emancipatório (TONET, 2014), e que a mediação de tais conteúdos exige do docente o domínio de conhecimentos didático-pedagógicos e outros mais, bem como a compreensão de que seu trabalho constitui uma particularidade de uma totalidade social concreta.

O trabalho de Brito (2011) trata da constituição do ciclo de vida profissional de professores de Licenciatura em Ciências Biológicas, do Instituto de Biologia (INBIO) da Universidade Federal de Uberlândia (UFU) e buscou compreender como os referidos docentes constroem seu ciclo de vida profissional a partir de suas bases formativas e de trabalho; e aferir como a ideia de carreira docente vem se consolidando a partir das relações tecidas entre trabalho, sujeito, universidade e como ocorre o processo de reconhecimento do ser professor na caminhada profissional desses sujeitos na universidade.

A pesquisa permitiu concluir que existe um ciclo de vida profissional que acontece de forma individual e coletiva, que se constrói no dia a dia de suas trajetórias articuladas às suas carreiras. Destaca que entre os professores mais antigos há uma compreensão mais nítida sobre os processos de intensificação do trabalho docente na universidade e para os professores mais novos a de que falta uma política de definição de papéis para aqueles que já estão e para os que estão chegando. A maioria deles focou o Doutorado como um marco importante de mudança de sentido da docência e do seu encontro com o ser professor, por essa titulação associar-se ao sentimento de autonomia acadêmica.

Anteriormente a este trabalho de tese, Brito (2006), em sua dissertação de mestrado, investigou as representações de professores formadores de professores de Biologia, também do Instituto de Biologia da Universidade Federal de Uberlândia sobre docência e como essas representações sociais impactam em sua prática docente. A pesquisa revelou que a docência está mergulhada num universo de representações que constituem a maneira como os sujeitos a concebem (formar o ser humano, é uma arte, é ser professor, é sala de aula, é ensino, é carreira, é atividade docente), e uma delas está vinculada à representação de universidade, que temos construída, principalmente pela forma como ela elabora, separa e classifica as atividades desenvolvidas pelos professores, a exemplo da Gratificação de Estímulo à Docência (GED), dos Formulários para Progressão de Carreira, dos Relatórios da Capes, as quais constituem-se na materialização da forma como a universidade concebe a docência dentro dela e como ela passa a ser gerada no dia-a-dia da vida universitária.

Destacamos que esse aspecto regulatório sobre o trabalho do docente do Ensino Superior, identificado na pesquisa de Brito (2006), constitui importante determinação da 
práxis dos professores, sobretudo como expressão da reestruturação dos processos de trabalho, de sua flexibilização e da produção de mercadorias, resposta do capital à crise da década de 1970 (MANCEBO, 2010). A pesquisa também enfatiza que a ausência das discussões a respeito da formação do professor, do seu exercício como tal, das questões que propiciam ao sujeito reconhecer a docência como uma atividade, também contribui para promover visões restritas acerca da docência, e aqui percebemos, mais uma vez, que a formação dos professores do ensino superior se expressa como uma determinação importante de seu trabalho. Por fim, conclui que as representações encontradas entre os professores são diversificadas, impregnadas de valores e de subjetividade, frutos de uma construção histórica, embebida de representações culturais, sociais e políticas.

A pesquisa de Madeira (2014) traz o trabalho do docente universitário implicado na formação de professores de Biologia, caracterizado como hibridismo epistemológico. Investiga como os professores de disciplinas específicas se implicam na formação inicial dos licenciandos, tendo como centralidade os seus processos formativos e identitários, no contexto de alterações curriculares dos cursos de Ciências Biológicas da União Metropolitana de Educação e Cultura (UNIME) e da Universidade Estadual de Feira de Santana (UEFS).

A pesquisadora conclui que os professores de disciplinas específicas das licenciaturas em Ciências Biológicas estudadas se identificam com a função de professor e de formador por um processo de hibridismo epistemológico e formativo. Isso ocorre na medida em que recontextualizam, através de seus etnométodos, processos formativos de naturezas diversas, por vezes contraditórias. Destacam-se os processos identitários relacionados à episteme de diferentes campos - ciências naturais e humanas - e aos diferentes componentes e fontes da sua formação - heteroformação, com base em modelos e autoformação pela prática. Conclui, ainda, que a trajetória formativa deles imprime marcas definidoras da singularidade profissional e pessoal de cada um; e que há um ciclo reprodutor de um processo que tem sua origem na constituição do sujeito formador e sua continuidade na ação profissional deste, indicando uma forte relação entre as concepções e práticas formativas e concepções e práticas educativas formadoras de professores.

Furlani (1994) se propôs a diagnosticar as características do professor de Biologia formado no curso de licenciatura da Universidade Federal de Santa Catarina (UFSC), bem como os aspectos de sua formação, dentre os quais focou: a estrutura do curso e seu enfoque disciplinar, bem como no perfil do corpo docente que atua nesse processo de formação. Para tanto, constituíram-se sujeitos da pesquisa licenciandos, licenciados que já atuavam na Educação Básica e professores dos diversos departamentos participantes dessa formação. $\mathrm{O}$ 
estudo fundamentou-se na discussão de Habermas, que através da Teoria Crítica da Educação, define conceitos de multidisciplinaridade e interdisciplinaridade, confrontando-os com o processo de fragmentação do conhecimento científico e em Gusdorf, que apresenta seus conceitos de forma aplicada no ato pedagógico.

Partindo das características estruturais do curso e da responsabilidade e atuação de seu corpo docente, a análise do processo de formação dos professores de Biologia revelou a necessidade de integração desses aspectos sob a mediação da realidade global do Ensino Básico, onde os profissionais formados irão atuar. Tal preocupação também levantamos em torno de nosso objeto de estudo, uma vez que muitos professores dos cursos de licenciatura nunca exerceram o magistério, profissionalmente, na Educação Básica, ou como alerta Mello (2000, p. 100):

Os cursos de graduação são ministrados num contexto institucional distante
da preocupação com a educação básica, que não facilita nem mesmo a
convivência com pessoas e instituições que conhecem a problemática desta
última. Os professores formadores que atuam nesses cursos, quando estão
em instituições de qualidade, são mais preocupados com suas investigações
do que com o ensino em geral, e menos interessados ainda no ensino da
educação básica.

A pesquisa de Furlani (1994, p.122) revela, ainda, que "há uma nítida contradição por parte dos docentes formadores no que diz respeito às suas concepções sobre o que deve ser um professor de Biologia e sua prática em sala de aula", ou seja, "uma dificuldade entre a teoria e a prática daquilo que os docentes formadores consideram importante num professor e daquilo que conseguem ser em sala de aula" (Idem, ibidem). Esse aspecto nos chamou atenção por dizer, diretamente, sobre os limites do trabalho dos professores na licenciatura em Ciências Biológicas, o que corrobora com os estudos desenvolvidos no campo da docência universitária.

Outro aspecto importante que o estudo de Furlani (1994, p. 122) apresenta é que "a reflexão epistemológica por parte dos docentes formadores é muito reduzida (ou quase inexistente), o que lhes impede de perceber ideologias perpassadas no conhecimento transmitido através das disciplinas".

Aqui, também pontuamos que essa condição caminha na contramão da constituição de atividades educativas de caráter emancipatório, pois como defende Tonet (2014, p. 12), “o caráter emancipador de qualquer atividade resultará de sua conexão, direta ou indireta, com o objetivo final, neste caso, com a construção de uma sociedade plenamente livre”. Se os trabalhadores docentes não reconhecerem as ideologias que atravessam os conteúdos das 
disciplinas que ministram junto aos estudantes, e no caso específico das licenciaturas, junto aos futuros professores, dificilmente poderão pôr em movimento a mediação do conhecimento numa perspectiva ontológica da educação e do projeto de superação da sociedade de classes.

A pesquisa também revelou que os formadores demonstraram falta de interesse para com as questões pedagógicas, privilegiando o bacharelado, através da ênfase dada às atividades de pesquisa, e que as principais dificuldades encontradas no dia-a-dia da sala de aula pelos licenciandos da UFSC estão relacionadas com a questão estrutural do curso (inexistência de relação entre as disciplinas durante seu processo de formação), aliado à inadequação dos conteúdos das disciplinas universitárias com a realidade do Ensino Básico, assim, as disciplinas desarticuladas, somadas às questões de infraestrutura do curso, comprometem a formação dos licenciandos.

Tal situação ainda não foi superada, mais de duas décadas depois da pesquisa de Furlani (1994), como revelam os estudos no campo da formação de professores e da docência universitária, apesar de as Diretrizes Curriculares Nacionais para a Formação de Professores da Educação Básica, publicadas em 2002, orientarem os cursos de licenciatura sobre a necessidade priorizar a articulação dos conteúdos acadêmicos aos escolares e sua mediação junto aos estudantes do Ensino Fundamental e Médio.

A autora conclui:

A formação profissional e pedagógica do futuro professor de Biologia deve
ser repensada e fortalecida, sendo necessária uma definição clara nas
concepções básicas da formação do educador, direcionando ação docente e
institucional, nesta busca, de forma integrada. [...] A sua competência
constrói-se gradativamente ao longo do seu processo de formação e na sua
prática escolar, a partir de uma opção pedagógica, de uma opção política, da
produção e difusão do conhecimento, do trabalho educativo junto às massas
e da constante reorganização do saber sistematizado. (FURLANI, 1994, p.
121-125).

Os trabalhos analisados apontam para a intensificação do trabalho do professor na licenciatura em Ciências Biológicas (BRITO, 2011); que o desenvolvimento desse trabalho se dá por meio de um hibridismo epistemológico (MADEIRA, 2014), o qual acreditamos que precisa ser melhor compreendido e discutido no campo do trabalho desenvolvido na formação de futuros professores de Biologia e os impactos desse processo no tocante aos limites e possibilidades para um trabalho docente de caráter emancipatório. E como destaca o trabalho de Brito (2006), a pouca discussão sobre formar professores no âmbito do trabalho que os docentes desenvolvem na licenciatura em questão restringe sua visão acerca da docência e de suas implicações, o que para nós pode contribuir para o estranhamento do professor em 
relação ao trabalho que desenvolve. E por fim, o trabalho de Furlani (1994) que nos instiga a conhecer em que se fundamentam as concepções e teleologias que orientam o trabalho docente no âmbito da formação de professores de Biologia para a Educação Básica.

Ainda no âmbito da licenciatura em Ciências Biológicas, no tocante à prática pedagógica, o estudo de Bizarro (2005) acrescenta elementos às investigações de Ferreira (2010). Buscou a compreensão do significado da Didática na prática pedagógica de professores de cursos de licenciatura, incluindo professores da Licenciatura em Ciências Biológicas, tendo como premissa a percepção dos mesmos sobre a Didática no desenvolvimento de seu trabalho, do qual se permitiu concluir que os professores a valorizam, mas que se faz necessário dar continuidade à formação, sobretudo em aspectos pedagógicos.

Entendemos que a universidade, pelo papel que lhe é conferido no processo de reprodução social, necessita assumir uma perspectiva emancipatória no tocante à formação de seus docentes (para o desenvolvimento das atividades de ensino, pesquisa, extensão e gestão), trazendo para o cerne de suas ações formativas a centralidade do trabalho e a necessidade de contribuir para que seus professores possam desenvolver uma práxis criadora, revolucionária. A maioria das pesquisas no âmbito da docência universitária trazem a centralidade na formação, sem discutir mais detidamente seus fins em articulação com o trabalho, bem como a relação trabalho/educação em seu sentido ontológico, na direção do enfrentamento e da superação da sociedade de classes.

Analisamos, agora, mais detidamente, o estudo de Martelli (2004). A investigação buscou, a partir da colaboração dos sujeitos, propor referenciais teórico-metodológicos necessários para nortear a construção da prática pedagógica dos docentes universitários e compor a formação do licenciado em Ciências Biológicas, de forma que venha a atender aos desafios do ensino na sociedade atual.

A pesquisa identificou que:

A concepção de ciência aceita pelo professor é o caminho que orientará sua prática pedagógica, [...] e que, para muitos docentes, a ciência é uma atividade humana, numa tentativa de entender e representar a realidade do mundo. (MARTELLI, 2004, p. 74).

Esse achado da investigação dialoga, proximamente, com o conjunto de atividades constituem a práxis docente do professor formador. Entendemos que essa práxis se concretiza pela objetivação de pores teleológicos que se vinculam a tais concepções, que podem aproximar ou distanciar o fazer docente de uma perspectiva transformadora, emancipatória, como na acepção de Tonet (2014). 
A pesquisa de Martelli (2004, p. 75) informa que:

[...] os professores identificam o conhecimento básico da área específica e dos aspectos didático-pedagógicos como indispensáveis, mas revelam uma preocupação com a formação de cidadãos críticos e responsáveis, interessados no trabalho de pesquisa com uma visão holística, principalmente, dos desafios ambientais. Infelizmente, muitos professores ainda estão enraizados no paradigma tradicional e suas principais preocupações são: os conteúdos, a carga-horária e a falta de recursos.

As condições objetivas que os professores apontam, além dos aspectos que julgam importantes na composição do perfil dos licenciandos em Ciências Biológicas, surgem, em nosso entendimento, como determinações do trabalho docente e, portanto, não devem estar associadas como questões enraizadas em um paradigma tradicional, ou serem tratadas como uma questão menor.

A análise das propostas apresentadas pelos professores formadores permitiu, segundo Martelli (2004), construir um quadro referencial que indicasse pontos norteadores significativos para compor a prática pedagógica do futuro professor de Ciências Biológicas. Segundo a autora, apontam caminhos que possam atender aos desafios da sociedade atual: superar a fragmentação; participação dos alunos no processo educativo; formar cidadãos; vivenciar a prática; formação continuada dos professores universitários; e propiciar um espaço para discutir a natureza do conhecimento científico. E conclui que:

[...] é necessário um esforço coletivo para reformar a docência e iniciar um processo de transformação da educação. Para que ocorra a transformação, é preciso que os professores acreditem no que estão fazendo. A opção pela mudança real e verdadeira deve se iniciar pela alteração paradigmática, ou seja, assumir um processo de busca da ciência para a transformação da sociedade (p.79).

Esta última citação que extraímos do trabalho de Martelli (2004) aponta para a necessidade urgente de discutirmos a indissociabilidade entre condições objetivas e subjetivas de realização do trabalho docente, porque entendemos a educação como mediação essencial ao processo de reprodução e transformação social. O que não tem sido explicitado nas investigações é o sentido dessa transformação, ou quanto apontado, é, geralmente, sinalizado na direção da formação de um cidadão crítico e reflexivo, sem a discussão dessas categorias no âmbito da sociedade de classes e das relações de exploração que se expressam no desenvolvimento do trabalhado docente.

O trabalho de Martelli (2004), assim como os de Madeira (2015) e Furlani (1994), aglutina preocupações com o desenvolvimento de um trabalho docente comprometido com a 
transformação social, o que se aproxima do nosso entendimento de que esse trabalho precisa ser desenvolvido numa perspectiva emancipatória, como particularidade de uma totalidade social, concreta, em sua historicidade, condição sinequa non para que a teleologia orientadora do trabalho do professor formador na licenciatura em Ciências Biológicas caminhe direção sinalizada pelas autoras.

\subsection{O que dizem as produções do Portal. Periódicos. CAPES?}

As produções localizadas no Portal de Periódicos CAPES (Base Scielo Brazil) tiveram focos diversos e, no âmbito da formação inicial de professores de Biologia, encontram-se os estudos de Massabini (2011) e Pereira (2000), os quais apontam aspectos intrinsecamente relacionados ao trabalho docente dos professores formadores.

No contexto dos estudos com foco na formação docente inicial, Massabini (2011) buscou relacionar as formas de licenciandos em Ciências Biológicas, de uma universidade pública paulista, conceberem os conflitos durante o estágio supervisionado a indícios de desenvolvimento da profissionalidade, do que resultou a necessidade de se trabalhar com as escolas-campo de estágio e de essa atividade ser acompanhada pelo professor formador no cotidiano da escola.

Partindo da conclusão desse estudo, é importante destacar que o acompanhamento dos licenciandos nas escolas pelos docentes formadores imprescinde de condições objetivas para tal, incluindo o traslado do docente, da universidade às escolas-campo de estágio, cargahorária destinada a esse acompanhamento, além da quantidade de estudantes que ficam sob a responsabilidade do professor formador, aspectos, geralmente, negligenciados.

Pereira (2000) realizou uma investigação sócio-histórica no Curso de Ciências Biológicas da Universidade Federal de Minas Gerais, onde buscou subsídios para uma melhor compreensão da situação atual de menor status acadêmico das licenciaturas nas universidades brasileiras e das consequentes dificuldades enfrentadas por esses cursos para implementação de mudanças significativas.

Sua investigação constituiu-se como um Estudo de caso e se ancorou nas categorias bourdiesianas de habitus e campus. Chegou à conclusão de que o menor status acadêmico das licenciaturas em relação ao bacharelado, do ensino em relação à pesquisa, assim como da graduação quando comparada à pós-gradudação, é "reflexo das relações de força, das lutas e estratégias dos interesses e lucros estabelecidos no campo universitário brasileiro desde sua origem" (PEREIRA, 2000, p. 200). 
Assim, destaca que os desafios a serem enfrentados no âmbito da formação de professores com vistas à elevação da sua qualidade situam-se para além de uma reforma curricular, mudanças em ementas e na carga-horária das disciplinas, ou na concepção de formação de professores que se tem hoje nas universidades. Nesse sentido, denuncia que:

\begin{abstract}
A não-valorização do profissional da educação e seus salários aviltantes, as precárias condições de trabalho e a falta de um plano de carreira para a profissão continuam sendo problemas fulcrais que prosseguem sem solução em nosso país e que afetam diretamente as questões da formação inicial de professores. (PEREIRA, 2000, p. 200-201).
\end{abstract}

As questões apontadas por Pereira (2000), no âmbito do curso de Ciências Biológicas, se constituem determinações importantes no tocante ao trabalho do professor formador, na direção e na forma do desenvolvimento de sua práxis. Estão articuladas a questões mais amplas no contexto histórico da educação brasileira, marcado por interesses e relações antagônicas de classe.

A investigação de Gatti (2010) se deteve na formação de professores no Brasil a partir da legislação relativa à essa formação, assim como das características sócio-econômicas dos licenciandos, dos cursos formadores, currículos e ementas destes. Os cursos em questão foram de licenciatura em Pedagogia, Matemática, Língua Portuguesa e Ciências Biológicas. A pesquisadora alerta para aspectos preocupantes, destacando que mereciam maior atenção as ambiguidades das normatizações vigentes, a fragmentação entre e intra cursos, a parte dedicada à formação específica para o trabalho docente, incluindo os Estágios.

Outro aspecto tratado nos estudos foi a formação continuada de professores de Ciências e Matemática em articulação com a Educação Básica. Freitas, Carvalho e Oliveira (2012) olham para a formação de professores das licenciaturas em Física, Biologia e Matemática, participantes de um curso de formação contínua para professores da Educação Básica, e concluem que a interação entre professores universitários e entre estes e os professores das escolas possibilitou a produção de conhecimentos sobre a docência, ou seja, o envolvimento dos professores universitários forneceu condições para sua formação para a docência, o que, em nosso entendimento, pode sinalizar ganhos qualitativos no trabalho desenvolvido pelos professores na licenciatura.

Os trabalhos sinalizam a necessidade de se discutir as condições objetivas e as matrizes teórico-metodológicas que estão postas às licenciaturas e ao trabalho docente que nelas é desenvolvido, o que, em certa medida, podem obstaculizar seu desenvolvimento numa perspectiva emancipatória. 
3.3 O que dizem as produções das Reuniões Anuais da Associação Nacional de Pósgraduação e Pesquisa em Educação - ANPED (2000 -2015)?

Nos Anais da Anped localizamos quarenta (40) produções que versam sobre o trabalho docente e as classificamos, conforme explicitado no quadro3:

Quadro 3 - Distribuição e classificação dos trabalhos por GT (2000 - 2015). (TD - Trabalho Docente; TDES Trabalho Docente no Ensino Superior; TDL - Trabalho Docente na Licenciatura; TDLCB - Trabalho Docente na Licenciatura em Ciências Biológicas)

\begin{tabular}{|l|l|l|l|l|l|}
\hline GT & TD & TDES & TDL & TDLCB & TOTAL/GT \\
\hline 04 & 03 & 01 & 04 & 00 & 08 \\
\hline 08 & 06 & 02 & 04 & 01 & 13 \\
\hline 09 & 16 & 02 & 01 & 00 & 19 \\
\hline TOTAL & 25 & 05 & 09 & 01 & 40 \\
\hline
\end{tabular}

Fonte: Elaboração das autoras.

A partir do quadro 3, podemos destacar que 37,5\% (15) das produções inventariadas sobre trabalho docente dialogam com essa atividade no âmbito do Ensino Superior. A maioria está concentrada no GT 09 - Trabalho e Educação, 47,5\% (19), mas destas, apenas três (03) realizadas no âmbito do Ensino Superior, sendo uma (01) na Licenciatura, mas não em Ciências Biológicas. Apenas um (01) estudo, dentre os quarenta (40) que foram localizados na Anped, sobre Trabalho Docente, trata dessa práxis na referida licenciatura (SILVA; SCHNETZLER, 2004), no período mencionado (2000-2015). O estudo teve foco na formação inicial de professores de Ciências/Biologia, revelando importantes limitações do trabalho docente em relação à formação dos futuros professores para atuar na Educação Básica. Destaca a insuficiência de preparação dos futuros professores quanto ao domínio dos conteúdos da matéria a ensinar.

Nos Anais da Anped (GT - 04) localizamos, ainda, uma segunda produção (TEIXEIRA, 2012) que, embora não explicite em seu título as expressões trabalho docente e/ou licenciatura em Ciências Biológicas e, portanto, não componha o conjunto dos quarenta (40) trabalhos sinalizados no quadro 3, foi realizada no âmbito da referida licenciatura. Teve como foco a mediação didática no processo de formação e desenvolvimento da profissionalidade docente em cursos de licenciatura. O estudo foi desenvolvido tendo como sujeitos professores das Licenciaturas em Biologia, Música e Pedagogia.

O estudo permitiu concluir que há uma preocupação em trabalhar a formação profissional dos estudantes a partir da mobilização de saberes profissionais, muito embora 
esses saberes não tenham sido claramente definidos. Existe entre eles uma preocupação, por decorrência, em se trabalhar em prol do desenvolvimento da profissionalidade docente no seio do curso, mas também não há muita clareza sobre as formas pelas quais esse processo pode e deve ser trabalhado.

Em relação, especificamente, aos docentes da licenciatura em Ciências Biológicas, a pesquisadora inferiu que os professores de Biologia são os mais imprecisos em suas definições sobre os saberes pedagógicos e sobre a construção da profissionalidade docente no curso. No tocante aos professores desta licenciatura, Teixeira (2012) percebeu algumas contradições, assim como respostas inconsistentes, o que pode revelar uma lacuna na formação pedagógica dos profissionais, já que, a maioria destes é biólogo com pós-graduação em áreas específicas da Biologia e nenhuma formação mais ampla na área pedagógica. A autora afirma a existência de uma distância abissal entre o que dizem os mais atuais compêndios da ciência pedagógica e a prática pedagógica dos professores da educação superior.

Os estudos levantados colaboram para aprofundar e robustecer a problematização acerca do trabalho docente desenvolvido no curso de licenciatura em Ciências Biológicas. Ao mesmo tempo em que os achados da Anped revelam a escassez de publicações sobre essa licenciatura específica em uma das Associações brasileiras mais relevantes no âmbito da Pesquisa em Educação e a necessidade de investigações com foco no trabalho docente voltado para a formação de professores de Ciências e Biologia para a Educação Básica, pois do total de setecentas e cinquenta e quatro (754) produções localizadas na Anped, no período de 2000 a 2015, nos GT 04, 08 e 09, localizamos apenas dois (02) trabalhos desenvolvidos no âmbito da Licenciatura em Ciências Biológicas.

3.4 O que dizem as produções do Banco de Teses e Dissertações do Programa de Pósgraduação em Educação da Universidade Estadual do Ceará (PPGE - UECE)?

O Banco de Dados do PPPGE/UECE (2006- 2017) armazena cento e oitenta e duas (182) produções (178 dissertações e 4 teses), das quais selecionamos vinte e um (21) trabalhos. Destes, destacamos duas (02) dissertações (CARDOSO, 2011; LOTFFI, 2014) e uma (01) tese (MEDEIROS, 2017) que tiveram como locus o curso de licenciatura em Ciências Biológicas, do Centro de Ciências da Saúde da Universidade Estadual do Ceará.

O trabalho de Cardoso (2011) discute a prática docente universitária dos professores formadores na perspectiva da integração ensino e pesquisa, tendo como orientação os 
documentos legais que balizam a formação de professores da educação básica e indicam a pesquisa como princípio formativo.

$\mathrm{O}$ autor conclui que os professores formadores detêm interesses de pesquisa dissonantes ao objetivo do curso, ou seja, formar professores para a Educação Básica. As práticas evidenciam desconexão entre teoria e prática, por conseguinte, pesquisa e ensino, havendo momentos pontuais de promoção do conhecer na ação, seguidos por reflexão-naação, promovido intuitivamente pelos docentes baseados em seus sabres da experiência.

Já a pesquisa de Lotffi (2014) se voltou para a práxis pedagógica dos professores formadores e as contribuições da Didática para o exercício da docência. Sua pesquisa identificou que os professores procuram desenvolver uma ação docente que vai além da dimensão técnica, constituindo-se de conhecimentos e conteúdos práticos, contextualizados, valorizando o respeito e o relacionamento afetivo entre professor e aluno. Buscam superar a dicotomia teoria-prática, por meio do ensino, da pesquisa e da práxis pedagógicas, embora pareçam ainda estar distantes de efetivá-las, conforme o estudo de Cardoso (2011).

E por fim, a investigação de Medeiros (2017) trata dos significados produzidos pelo currículo de licenciatura e sua relação com a identidade docente dos professores do curso. Os docentes compreendem a reestruturação curricular como um momento difícil, que impactou a realidade do curso, significando mudanças na estrutura formativa do curso, entendida como ideal para a formação do biólogo, e do enfrentamento solitário de desafios relacionados à formação de professores. No entanto, esses docentes consideram a reforma curricular ter sido um avanço, pois essa nova realidade produziu conhecimentos e propiciou o surgimento de novas posturas relativas à prática docente no curso de Ciências Biológicas.

\section{Considerações finais}

Nas buscas realizadas no site do PPGE/UECE, assim como na BDTD, no Portal. Periódicos.CAPES (Base Scielo) e nas Reuniões Anuais da ANPED, não encontramos produções que tratassem diretamente do trabalho docente desenvolvido na licenciatura em Ciências Biológicas, à luz da ontologia marxiano-lukacsiana, nem fundamentadas no Materialismo Histórico Dialético, embora tenhamos encontrado uma quantidade significativa de publicações problematizando o trabalho docente no Ensino Superior.

As investigações não o abordam como um complexo que tem sua gênese no trabalho (transformação da natureza pelo homem), ato fundante do ser social, mediação entre o indivíduo e o gênero humano, nem, ainda o buscam conhecer a partir do Materialismo 
Histórico Dialético, sinalizando uma lacuna no campo das investigações sobre o trabalho docente na licenciatura em questão e a possibilidade de nossa pesquisa contribuir para ampliar o debate no campo acadêmico-científico no tocante ao trabalho dos professores formadores nas licenciaturas e, no caso específico da formação de professores de Ciências e Biologia para a Educação Básica.

Os resultados das pesquisas que compõe este Estado da Questão - EQ consolidam o entendimento de que há limitações ao desenvolvimento do trabalho docente na licenciatura na perspectiva da emancipação humana, haja vista as fragilidades que marcam o processo formativo do docente universitário e os desafios que se lhes apresentam no campo da formação de professores, ainda inda que apontem que nas licenciaturas esse trabalho pode estar constituído por práticas que se aproximam e outras que se distanciam de uma perspectiva emancipatória.

Os estudos trazem a centralidade na formação, sem discutir mais detidamente seus fins em articulação com o trabalho, bem como a relação trabalho/educação em seu sentido ontológico, na direção do enfrentamento e da superação da sociedade de classes. As investigações sobre a formação de professores chamam atenção para as fragilidades na formação inicial, o que, a nosso ver, justifica a necessidade de estudos que busquem compreender as teleologias que orientam o trabalho do docente formador nas licenciaturas, compreendendo o trabalho docente como uma mediação, uma particularidade que integra a totalidade social concreta e a expressa, sobretudo suas contradições e a possibilidade de superações destas.

\section{REFERÊNCIAS}

BIZARRO, Adelina Maria Salles. O significado da Didática na formação do profissional docente: um olhar a partir da prática do professor do ensino superior. 2005. 155f. Dissertação (Mestrado Intersinstitucional UFPE/UPE). Programa de Pós-graduação em Educação. Universidade Federal de Pernambuco, Recife, 2005.

BRITO, TalamitaTaitaRogrigues. $O$ ciclo de vida profissional dos professores de Biologia da Universidade Federal de Uberlândia: trajetórias, carreira e trabalho. 2011. 370f. Tese (Doutorado em Educação) - Programa de Pós-graduação em Educação. Universidade Federal de Uberlândia, Uberlândia, 2011.

BRITO, TalamiraTaita Rodrigues. A docência no Instituto de Biologia da Universidade Federal de Uberlândia: percorrendo caminhos e encontrando representações. 2006. Dissertação (Mestrado em Educação). Universidade Federal de Uberlândia, Uberlândia, 2006. 
CARDOSO, Nilson de Souza. Como ensinam os professores de Ciências Biológicas?um estudo sobre a relação pesquisa e ensino na prática docente. 2011. 109f. Dissertação (Mestrado em Educação) - Programa de Pós-Graduação em Educação. Universidade Estadual do Ceará, Fortaleza, 2011.

FERREIRA, Daniele Rodrigues Macedo. Formação de professores de Biologia: Visões de práticas dos formadores do curso de Ciências Biológicas da UFG. 2010. 155f. Dissertação (Mestrado em Educação em Ciências e Matemática). Universidade Federal de Goiânia, Goiânia, 2010.

FREITAS, ZulindLuzmarinda; CARVALHO, Lizete Maria Orquizade. OLIVEIRA, Hernandes Rocha. Educação de professores da universidade no contexto de interação universidade-escola. Ciênc. Educ. [online], Bauru, v.18, n.2, p.323-334, 2012. Disponível em: http://www.scielo.br/pdf/ciedu/v18n2/a06v18n2.pdf . Acesso em: 02 set. 2016.

FURLANI, Jimena. A formação do professor de Biologia no curso de Ciências Biológicas da Universidade Federal de Santa Catarina: uma contribuição à reflexão.1994.153p.

Dissertação (Mestrado em Educação) - Programa de Pós-graduação em Educação. Universidade Federal de Santa Catarina, Florianópolis, 1994.

GATTI, Bernadete A. Formação de professores no Brasil: Características e problemas. Educ. Soc. Campinas, SP, v. 31, n.133, p. 1355-1379, out./dez. 2010. Disponível em: http://www.scielo.br/pdf/es/v31n113/16.pdf. Acesso em: 02 set. 2016

LOTFFI, Regina Célia Ribeiro. A práxis didático-pedagógica de docentes do Ensino Superior na perspectiva de professores do curso de Ciências Biológicas. 2014. 148f. Dissertação (Mestrado em Educação) - Programa de Pós-Graduação em Educação. Universidade Estadual do Ceará, Fortaleza, 2014.

\section{MADEIRA, Ana Maria Magalhães. UFBA. Licenciatura em Ciências Biológicas:} Hibridismo epistemológico e formativo na licenciatura em Ciências Biológicas: como os docentes de disciplinas específicas se implicam na articulação da formação inicial com a prática profissional. 2014. 140f. Tese (Doutorado em Educação) - Programa de Pósgraduação em Educação. Universidade Federal da Bahia, Salvador, 2014.

MANCEBO, Deise. Trabalho docente na Educação Superior brasileira: mercantilização das relações e heteronomia acadêmica. Revista Portuguesa, v. 23, n. 2, 2010, pp. 73-91. Braga, Portugal.

\section{MARTELLI, JosanneMilléo. Os desafios da prática pedagógica do Ensino de Ciências}

Biológicas frente às mudanças de paradigmas. 2004.85f.Dissertação.PUC/PR. 2004, Dissertação (Mestrado em Educação). Pontifícia Universidade Católica do Paraná, Curitiba, 2004.

MASSABINI, Vânia. Os conflitos de licenciandos e o desenvolvimento profissional docente. Educação e pesquisa [online], São Paulo, SP, v. 37, n. 4, p. 793 - 808, dez. 2011. Disponível em: http://www.revistas.usp.br/ep/article/view/28302/30155 . Acesso em: 02 jan. 2019.

MEDEIROS, Jeanne Barros Leal de Pontes. Currículo Significados e Sentidos do Currículo de Licenciatura: o que dizem os professores formadores de um Curso de Ciências 
Biológicas. 2017. 288f. Tese (Doutorado em Educação) - Programa de Pós-Graduação em Educação. Universidade Estadual do Ceará, Fortaleza, 2017.

MELLO, Guiomar Namo de. Formação de professores para a Educação Básica: uma (re)visão radical. Perspec., São Paulo, v. 14, n. 1, p. 98 -110. Jan./mar. 2000. Disponível em: http://www.scielo.br/pdf/spp/v14n1/9807.pdf. Acesso em 17 jan. 2019.

NUNES, João Batista Carvalho. Busca científica na pesquisa em Educação: tendências atuais. In: In: NÓBREGA-THERRIEN, Silvia Maria; Sabino de; NUNES, João Batista Carvalho. (Org.) Pesquisa científica para iniciantes: caminhando pelo labirinto. Fundamentos da Pesquisa. v. I. Fortaleza: EdUECE, 2011

PEREIRA, Júlio Emílio Diniz. Relações de poder no interior do campo universitário e as licenciaturas. Cadernos de Pesquisa, [online], n. 111, p. 182 -201, dez. 2000. Disponível em: http://www.scielo.br/pdf/cp/n111/n111a10.pdf . Acesso em: 02 jan. 2019.

SILVA, Lenice Heloísa de Arruda; SCHNETZLER, Roseli Pacheco. A elaboração conceitual na constituição docente de futuros professores de Ciências/Biologia: modos de mediação do formador. In: Reunião Anual da Associação Nacional de Pós-graduação e Pesquisa em Educação, 27. 2004, Caxambu. Disponível em:

http://27reuniao.anped.org.br/gt08/t0817.pdf. Acesso: 10 maio 2017

TEIXEIRA, Cristina Maria D'Ávila. Docência na educação superior e a construção da profissionalidade docente em cursos de licenciatura: continuidades e rupturas. In: Reunião Anual da Associação Nacional de Pós-graduação e Pesquisa em Educação, 35. 2012, Porto de Galinhas. Disponível em:

http://35reuniao.anped.org.br/images/stories/trabalhos/GT04\%20Trabalhos/GT041530_int.pdf. Acesso: 09 maio 2017.

THERRIEN, Jacques; NÓBREGA-THERRIEN, Sílvia Maria. Os Trabalhos Científicos e o Estado da Questão: reflexões teórico-metodológicas. Estudos em avaliação educacional, v.15, n.30, jul.-dez. 2004.

TONET, Ivo. Atividades educativas emancipadoras. Práxis Educativa, Ponta Grossa, v. 9, n. 1, p. 9 -23, jan./jun. 2014.

\section{SOBRE AS AUTORAS:}

\section{Maria Márcia Melo de Castro Martins}

Licenciada em Ciências Biológicas. Mestre e Doutoranda em Educação pelo Programa de Pós-graduação em Educação da Universidade Estadual do Ceará (PPGE/UECE). Profa. Assistente da Universidade Estadual do Ceará, vinculada ao Curso de Licenciatura em Ciências Biológicas/ Setor de Prática de Ensino. Membro do Grupo de Pesquisa Docência no Ensino Superior e na Educação Básica. E-mail: marcia.melo@uece.br 


\section{Maria Marina Dias Cavalcante}

Licenciada em Pedagogia. Mestre, Doutora e Pós-doutora em Educação. Profa. Associado Oda Universidade Estadual do Ceará, vinculada ao Curso de Pedagogia e ao Programa de Pós-graduação em Educação (PPGE/UECE). Líder do Grupo de Pesquisa Docência no Ensino Superior e na Educação Básica. E-mail: maria.marina@uece.br

\section{Elisangela André da Silva Costa}

Licenciada em Letras e em Pedagogia. Mestre, Doutora e Pós-doutora em Educação. Profa. Adjunta da Universidade da Integração Internacional da Lusofonia Afro-Brasileira (UNILAB). Vinculada ao Instituto de Ciências Exatas e da Natureza. Membro do Grupo de Pesquisa ELOSS - Educação e Cooperação Sul-Sul. E-mail: elisangelaandre@ unilab.edu.br 